\title{
THE ASSESSMENT OF RIVER ECOLOGY AND HABITAT USING A TWO- DIMENSIONAL HYDRODYNAMIC AND HABITAT MODEL
}

\author{
Ray-Shyan Wu \\ Department of Civil Engineering, National Central University, Chungli, Taiwan 320, R.O.C. \\ Chen-Tai Mao \\ 3F, No.3, Baocing Rd., Taipei, Taiwan, 10020, R.O.C., mctai@cepd.gov.tw
}

Follow this and additional works at: https://jmstt.ntou.edu.tw/journal

Part of the Civil and Environmental Engineering Commons

\footnotetext{
Recommended Citation

Wu, Ray-Shyan and Mao, Chen-Tai (2007) "THE ASSESSMENT OF RIVER ECOLOGY AND HABITAT USING A TWODIMENSIONAL HYDRODYNAMIC AND HABITAT MODEL," Journal of Marine Science and Technology. Vol. 15: Iss. 4, Article 7.

DOI: $10.51400 / 2709-6998.2049$

Available at: https://jmstt.ntou.edu.tw/journal/vol15/iss4/7

This Research Article is brought to you for free and open access by Journal of Marine Science and Technology. It has been accepted for inclusion in Journal of Marine Science and Technology by an authorized editor of Journal of Marine Science and Technology.
} 


\title{
THE ASSESSMENT OF RIVER ECOLOGY AND HABITAT USING A TWO-DIMENSIONAL HYDRODYNAMIC AND HABITAT MODEL
}

\author{
Ray-Shyan $\mathrm{Wu}^{*}$ and Chen-Tai Mao**
}

Key words: Phabsim, Rhabsim, evaluation of river ecology and habitat

\begin{abstract}
The assessment of river ecology is an integral part of river planning and management today. In any project, the simulation and quantification of river habitat and ecology is as important as the simulation of the hydrodynamics of the river. Currently in Taiwan, the use of one-dimensional models, such as Phabsim and Rhabsim, are widespread in the evaluation of river ecology and habitat. These models use data from the river cross-section and bed roughness coefficient to estimate habitat area. However, the use of these models is limited in small-scale or complex river conditions. This study applies a two-dimensional hydrodynamic and habitat model in combination with a continuous flow net to simulate topography and river dynamics. The 2-D model is used to estimate habitat area and its results are compared with the results of the 1-D model. Further analysis is given on the applicability and suitability of 2-D model use on small-scale or complex river conditions.
\end{abstract}

\section{FOREWORD}

The natural evolution of the river and its habitat manifests itself in the diversity of lifeforms that the river ecology can maintain. The river habitat is shaped by the quantity and velocity of waterflow. Changes in water flow velocity and the shape of the riverbed create different ecological niches such as pools, riffles, runs and glides. The riverbed itself can be divided into different gradients according to its riverbed material. These can include sand, gravel, aquatic vegetation, and cover. In one of his habitat studies, Osborne [3] defined the term "habitat" as "the place for the being to live and to exist". In summary, the river ecology habitat can defined as a niche where a target species can reside for a fixed period of time. The habitat required for each

Paper Submitted 08/30/06, Accepted 12/28/06. Author for Correspondence: Chen-Tai Mao. E-mail: mctai@cepd.gov.tw

*Department of Civil Engineering, National Central University, Chungli, Taiwan 320, R.O.C.

**3F, No.3, Baocing Rd., Taipei, Taiwan, 10020, R.O.C. species is variable depending on its life-phase, seasonality and behavior patterns. Traditionally, river management in Taiwan has focused on engineering works designed to supply water or to prevent floods. A typical construction work would go across the length of the channel thus effectively disrupting natural evolution of the river. The lack of concern paid to the ecological niches of the aquatic biota has meant a rapid decrease in available habitat. Additionally, the inadequate and belated construction of sewage pipes is reflected in the wanton dumping of wastewater causing severe pollution of the rivers and a corresponding decline in river ecology and habitat. Hence, several fish species unique to the island of Taiwan are on the brink of extinction. Recently, there has been a change in the general landscape of water management. Apart from flood prevention, concepts such as ecological conservation have gradually steeped into engineering construction. Nevertheless, these concepts have lacked practical content for application. This is especially true for Taiwan, where there is a considerable difference in river flow during the wet and dry seasons. Therefore, it is particular important to develop an assessment model of river ecology and habitat for analysis of natural conditions or as an aid in planning and management of a river. Via an assessment model of river ecology and habitat we can identify temporal or spatial changes of a river niche, and also the suitability of an environment for specific species.

Of late, Taiwan has imported one-dimensional hydrodynamic and habitat models for application on our rivers. For example, Yang [10] put one-dimensional hydrodynamic and habitat models in use to estimate the habitat of low river flow and. Wu et al. [9] to assess river baseflow. However, due to the limitations of cross-section data and the model itself, these models are effective on large-scale hydrodynamic and habitat conditions. Results from these models on areas with smaller-scale hydrodynamic and habitat conditions are generally recognized to have inherent flaws. This study uses DEM data to build a two-dimensional continuous net and simulate riverbed relief. The use of this methodology greater facilitates the simulation of regional 
hydrodynamic and habitat characteristics.

\section{METHODOLOGY}

This study will investigate the application of twodimensional hydrodynamic and habitat model River $2 \mathrm{D}$, and compare the results with those from one-dimensional hydrodynamic and habitat models. Due to the lack of in-situ flow velocity, water level and discharge data, therefore a preliminary simulation of those attributes was carried out using the HEC-RAS model [7]. Subsequently, the data variables were used for the onedimensional hydrodynamic and habitat model RAHBSIM [4]. The associated theories and details are described below

\section{HEC-RAS model}

One-dimensional hydrodynamic and habitat models can calculate subcritical, supercritical flow or mixed flow regime water surface profiles. As mentioned before, due to the lack of data, the HEC-RAS model was utilized to estimate flow velocity and water depth under different conditions of discharge. The HEC-RAS model mainly maks use of two equations. Eq. (1) is used to calculate water levels at different cross-sections of the river, while Eq. (2) is used to calculate hydraulic head energy loss. As follows:

$$
\begin{aligned}
& W S_{2}+\frac{\alpha_{2} V_{2}^{2}}{2 g}=W S_{1}+\frac{\alpha_{1} V_{1}^{2}}{2 g}+h_{e} \\
& h_{e}=L \bar{S}_{f}+C\left|\frac{\alpha_{2} V_{2}^{2}}{2 g}-\frac{\alpha_{1} V_{1}^{2}}{2 g}\right|
\end{aligned}
$$

Where $\mathrm{WS}_{1}, \mathrm{WS}_{2}$ denote water levels at different cross-sections. $\mathrm{V}_{1}, \mathrm{~V}_{2}$ represent water velocities at different cross-sections while $h_{e}$ is head loss.

\section{Phabsim and Rhabsim models (One-dimensional hy- drodynamic and habitat models)}

The PHABSIM and Rhabsim models incorporate two main components: the hydraulic model and the habitat model. They use IFIM (Instream Flow Incremental Methodology) to combine different aspects of hydrology and ecology to develop a set of habitat assessment software. Before simulating habitat conditions, the hydraulic model is run a number of times. Even so, this study uses the profile data generated by the HECRAS model to estimate the relationship between water depth and flow velocity. The habitat model initially partitions the interested river segment into $i$ number of computational cells (Figure 1). Using the results (flow velocity, water depth, riverbed material) obtained by the hydraulic model and the target species suitability curve imbedded in the habitat model, the weighted usable area (WUA) can be calculated by the following equation:

$$
W U A=\sum_{i=1}^{n} F\left[f\left(V_{i}\right), f\left(D_{i}\right), f\left(C_{i}\right)\right] \cdot A_{i}
$$

Where;
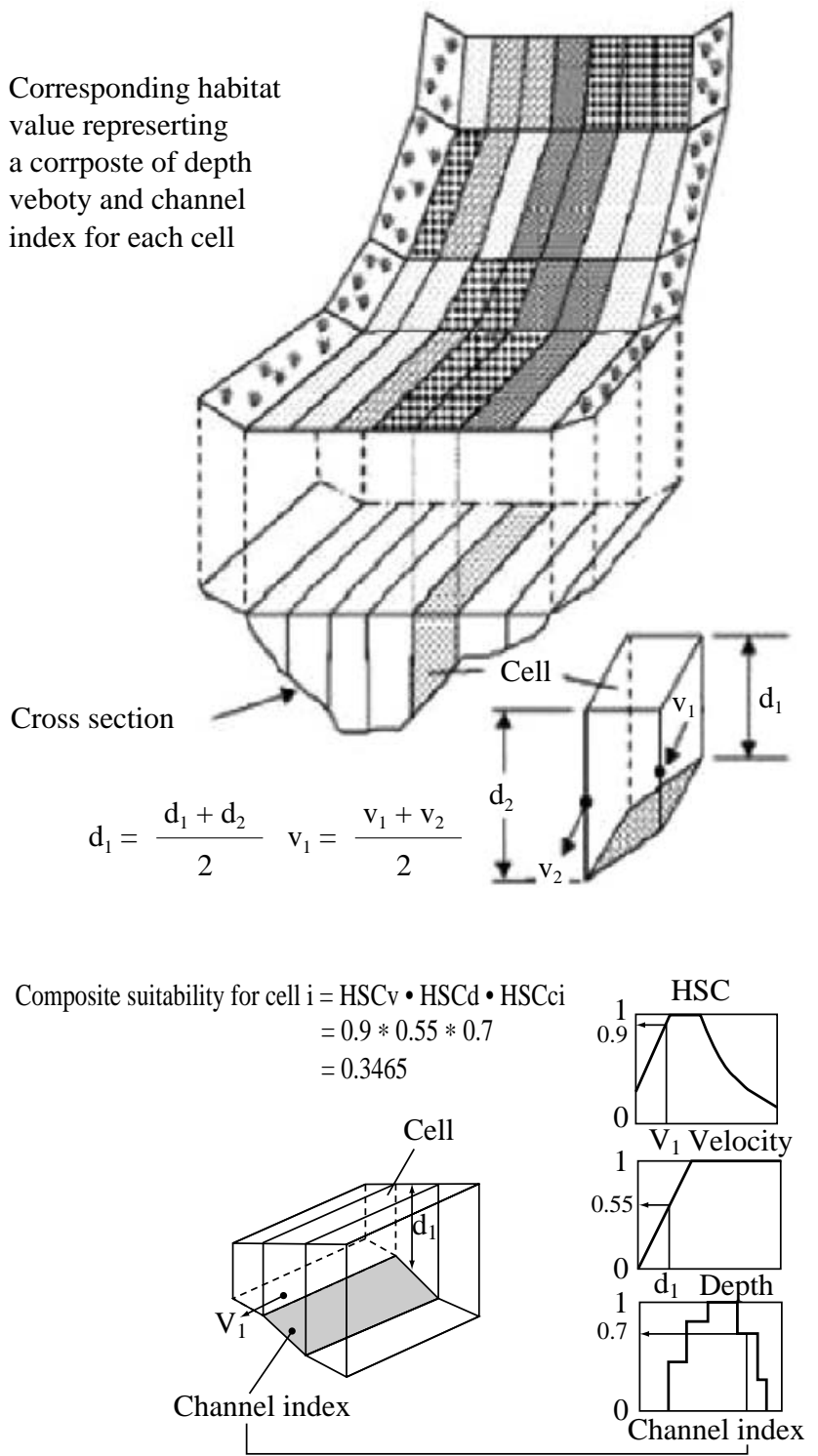

Fig. 1. Computational Cell of a habitat simulation model and Diagram of a habitat suitability curve [4]. 
$F[]=C S F=$ the composite suitability index for cell $i=$ $f\left(V_{i}\right) * f\left(D_{i}\right) * f\left(C_{i}\right)$

where

$f\left(V_{i}\right)$ is the suitability index associated with the velocity in cell $i$, and

$f\left(D_{i}\right)$ is the suitability index associated with the depth in cell $i$, and

$f\left(C_{i}\right)$ is the suitability index associated with the substrate type in cell $i$.

WUA is the surface area of a stream weighted by its suitability to an aquatic organism.

\section{Digital elevation model}

The net data prerequisite to running two-dimensional hydrodynamic and habitat models can be acquired through the Digital Elevation Model. The DEM is comprised by $\mathrm{x}, \mathrm{y}, \mathrm{z}$ coordinates. The DEM data for the area of Taiwan was collected by the Aerial Survey Office, Forestry Bureau. Analysis and digitization of the $3 \mathrm{D}$ aerial photos resulted in a resolution of $40 \mathrm{~m}$ by $40 \mathrm{~m}$ and files with a scale of 1/5000. Net data essentially transforms larger spatial units into smaller corresponding units, generally simplifying the data so that it is easier for the user to process. The size of the grid cell determines the resolution of the net data. The larger the grid size, the smaller the resolution, thus fewer objects can be represented on the map. The smaller the grid size, the higher the resolution, thus objects on the map can be viewed in great detail. The resolution of a typical DEM dataset can range from $40 \mathrm{~m} \times 40 \mathrm{~m}, 20 \mathrm{~m} \times 20 \mathrm{~m}$, $10 \mathrm{~m} \times 10 \mathrm{~m}$ and $5 \mathrm{~m} \times 5 \mathrm{~m}$. In a study by Huang et al. [1] the DEM was obtained through Light Detection and Ranging, LIDAR approach. The resolution of the DEM, $1 \mathrm{~m} \times 1 \mathrm{~m}$, is detailed enough to display topographical details of a smaller area and at the same time can eliminate surface buildings. This study employs a $5 \mathrm{~m} \times$ $5 \mathrm{~m}$ DEM in line with the $5 \mathrm{~m} \times 5 \mathrm{~m}$ DEM data collected by the government. Basic topographical DEM data is then inputted into the River 2D habitat model.

\section{River 2D habitat model}

River 2D habitat model is developed by Canada Freshwater Institute (FWI), Civil and Environmental Department of the University of Alberta, Midcontinent Ecological Science Center of the U.S. Geological Survey(MESC) and Fisheries Division of the Alberta Government. River 2D is a two-dimensional hydrodynamic and habitat model, and is comprised of 3 major components: R2D_Bed, R2D_Mesh, and River 2D.

\section{(1) $R 2 D \_B e d$}

This program is mainly used to input and edit topographical data. It uses a grid or Triangulated Irregular Network (TIN) method to edit and alter x, y, z coordinate data, in addition to defining the exterior boundary of the river. (Figure 2)

\section{(2) R2D_Mesh}

R2D_Mesh uses the data output from R2D_Bed and transforms it into relatively easy to use but effective computational mesh generating environment for twodimensional depth average finite element hydrodynamic modeling. (Figure 2)

\section{(3) River $2 D$}

This model simulates river natural conditions and habitat. The depth averaged model of River 2D is based on the conservation of mass and the conservation of momentum. Under the law of conservation of mass, it is assumed that there exists an imaginary column a stream flow, rectangular in plan (width and length $\Delta x$, $\Delta y$ ) and extending through the depth of water, $\mathrm{H}$, as shown in Figure 3. The equation for the law of conservation of mass is expressed below:

$$
\frac{\partial H}{\partial t}+\frac{\partial q_{x}}{\partial x}+\frac{\partial q_{y}}{\partial y}=0
$$

Where $\mathrm{q}_{\mathrm{x}}, \mathrm{q}_{\mathrm{y}}$ is discharge for coordinate $\mathrm{x}$ and $\mathrm{y}$.

Under the law of momentum, the average water depth for vectors $\mathrm{x}$ and $\mathrm{y}$ are show below:

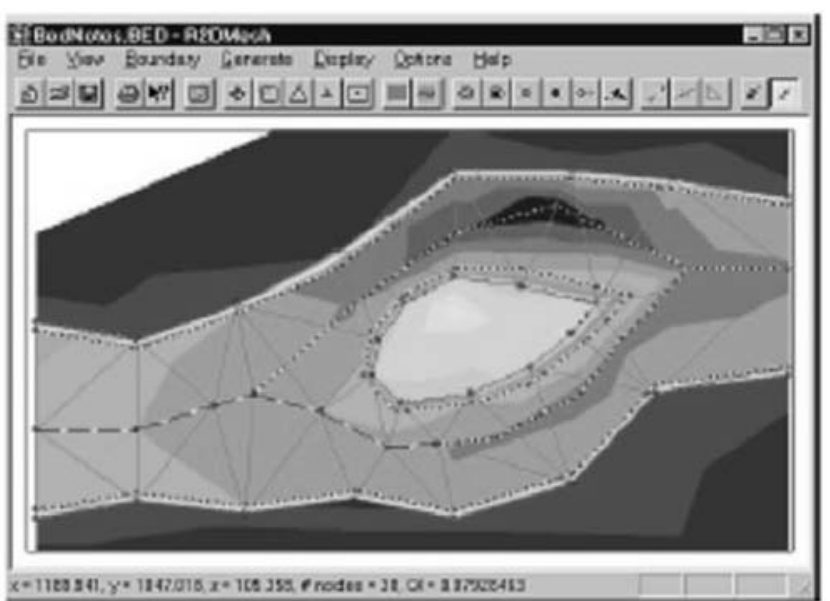

Fig. 2. A riverbed and flow net simulation diagram generated by R2D_Bed and R2D_Mesh [5]. 


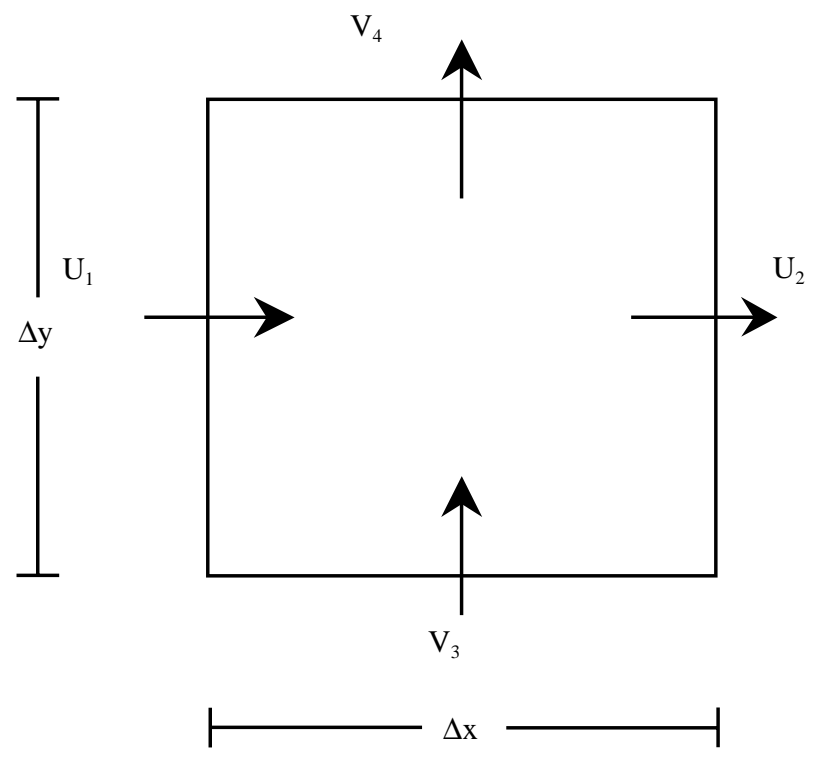

Fig. 3. Rectangular column used by River 2D to apply mass conservation law ( $U$ and $V$ are the flow velocity of vectors $x$ and $y$ ).

$$
\begin{array}{r}
\frac{\partial(\bar{u} h)}{\partial t}+\frac{\partial(\bar{u} \bar{u} h)}{\partial x}+\frac{\partial(\bar{u} \bar{v} h)}{\partial x}=\frac{\partial}{\partial x}\left(2 \overline{\varepsilon_{x x}} h \frac{\partial \bar{u}}{\partial x}\right) \\
+\frac{\partial}{\partial y}\left[\overline{\varepsilon_{x y}} h\left(\frac{\partial \bar{u}}{\partial y}+\frac{\partial \bar{v}}{\partial x}\right)\right]-\frac{\tau_{b x}}{\rho}-g h \frac{\partial H}{\partial x} \\
\frac{\partial(\bar{v} h)}{\partial t}+\frac{\partial(\bar{v} \bar{u} h)}{\partial x}+\frac{\partial(\bar{v} \bar{v} h)}{\partial y}=\frac{\partial}{\partial y}\left(2 \overline{\varepsilon_{y y}} h \frac{\partial \bar{v}}{\partial y}\right) \\
+\frac{\partial}{\partial x}\left[\frac{\partial \overline{\varepsilon_{x y}}}{\partial x}\left(\frac{\partial \bar{v}}{\partial y}\right)\right]-\frac{\tau_{b y}}{\rho}-g h \frac{\partial H}{\partial y}
\end{array}
$$

Where:

$\bar{u}, \bar{v}$ : water velocity for vectors $\mathrm{x}, \mathrm{y}$

$\bar{\varepsilon}$ : average eddy viscosity coefficient

$\tau_{b x}, \tau_{b y}:$ river bed shear stress on vectors $\mathrm{x}, \mathrm{y}$

The River 2D model applies the Galerkin formula of minimum weighted residual methods to solve the equations. The numerical modeling of depth averaged flow equations can then be carried out using the finite element model (FEM). Water depth and flow velocity can be solved using the continuity equation below:

$$
\int N_{i} C(H, U, V) d A=0
$$

$\mathrm{H}$ is water depth, $\mathrm{U}$ is flow velocity for vector $\mathrm{x}$, and $\mathrm{V}$ is flow velocity for vector $y$.

where $N_{i}$ is the $\mathrm{i}_{\text {th }}$ weight or test function. Integration over the area serves to reduce the spatial distribution to just a quantity.

River 2D divides the domain into discrete areas, and solves for river water depth and flow velocity using iterative finite element processes. (Figure 4)

River 2D hypotheses have three items as follows: a. The pressure distribution in the vertical is hydrostatic. Similarly, slopes in excess of about $10 \%$ will not be modeled correctly.

b. The distributions of horizontal velocities over the depth are essentially constant.

c. Coriolis and wind forces are assumed negligible.

A Bousinessq type eddy viscosity is used for the transverse shear in River 2D. The user is asked to input the inflow and the downstream water elevation to be the intial conditions for River 2D model. The user must draw the inflow boundary, outflow bounday and no crossflow boundary to be the boundary conditions.

\section{Habitat Types and riverbed substrate material}

The development of a river is exhibited by upstream, mid-stream and downstream river substrate gradation. Usually substrate media such as gravel, and other pebbles of uneven sizes can be found upstream. Conditions begin to change as we reach mid-stream, the stream starts to widen and the dynamics of pools, riffles, runs and glides are also affected. Sand and mud are the dominant substrate in this area of the river. In the lower reaches of the river, flow velocity is slow and the substrate typically consists of sand, mud and clay.

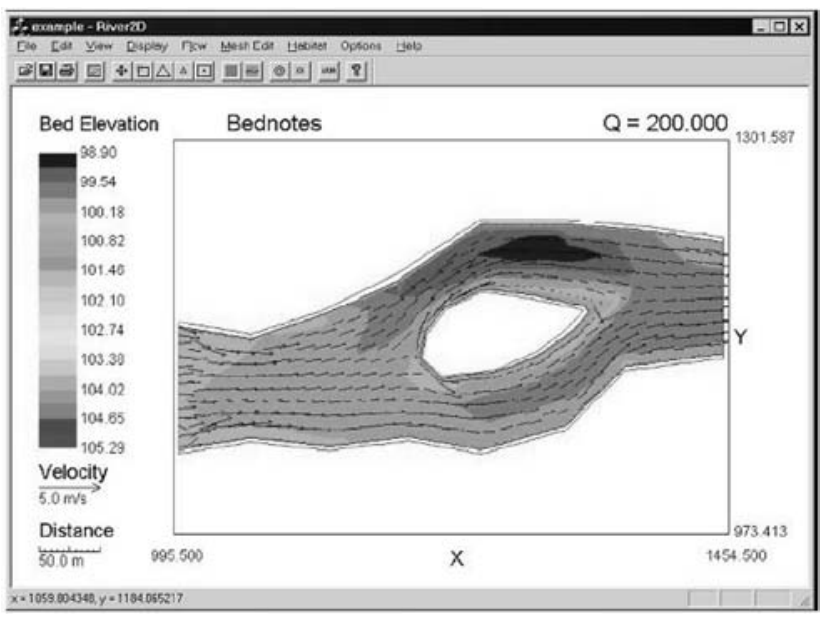

Fig. 4. River 2D simulation of flow velocity and water depth [6]. 
However, under disturbed conditions where there is excessive anthropogenic impact (caused by aquaculture or construction such as embankments, groundsill works and artificial wetlands), even on the same cross-section variation of substrate media can be observed. According to Moody's definition [2], roughness height $k s$ of a rough surface is the average height of all protruding objects on the surface. Figure 5 shows the substrate and bed roughness height coefficients for the application of River 2D in Elbow River as determined by United States Geological Survey, USGS. The actual coefficient used in the model is dependent on the in-situ riverbed substrate data collected. At a certain depth $\mathrm{H}$, the relationship between manning coefficient $n$ and $k s$ is as follows:

$$
k_{s}=\frac{12 H}{e^{m}}, m=\frac{H^{1 / 6}}{2.5 n \sqrt{g}}
$$

Figure 6 depicts the relationship between the 2 coefficients at the depths of $0.5,1,3$ and 5 meters.

\section{CASE STUDY AND ANALYSIS}

The research area is located on the mid-stream and downstream sections of Nankang River, Taoyuan County. This study simulates small-scale and complex river behavior in the study area using the two-dimensional hydrodynamic and the habitat model River 2D. We investigate how the substrate media affects habitat area and give a comparison of the results from onedimensional and two-dimensional hydrodynamic model and the habitat models. An analysis is also given on the effect of river construction on river habitat.

\section{Research area}

The source of the Nankang's main river originates from Niou-Jiao Slope at Ping-Ding-Tai-Di, Taoyuan. The valley is narrow and the slope is steep on the upstream end of the river. The rapid upstream water flow gradually begins to slow once the river reaches gentler slopes as it exits the mountainside next to HsinLu-keng, Guei-Shan Township. The river slowly meanders through Taoyuan City, Lu-zhu Township and Dayaun Township before finally discharging into the Taiwan Strait on the north side of Zhu-yuan Harbor. Gravel and sand form the main substrate of this region. Owing to the steep slope, whenever a flood occurs the fine sand and silt are directly washed out into the ocean while heavier cobbles such as gravel and sand are distributed evenly throughout the riverbed. According to the analysis of samples from 1979, the river substrate confirms the above, and shows that gravel and sand are indeed
Elbow river substrate and bed roughness height

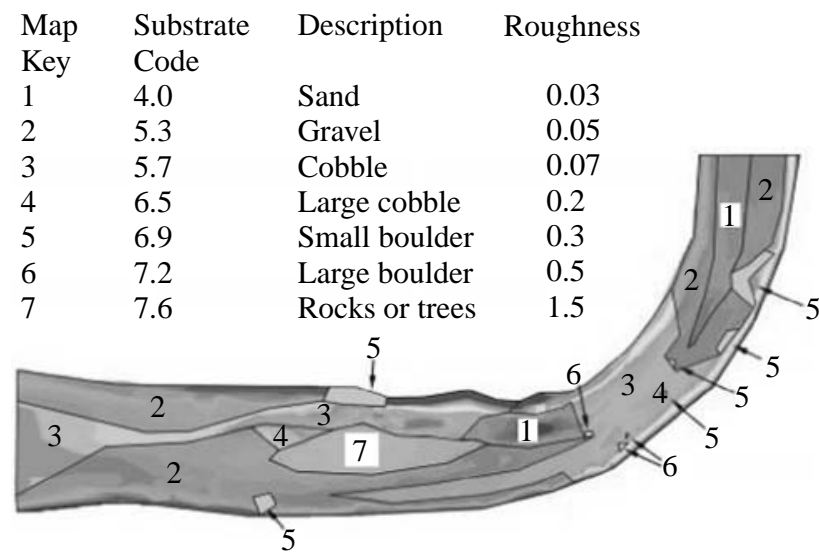

Fig. 5. Bed roughness coefficients for Elbow River substrate [8].

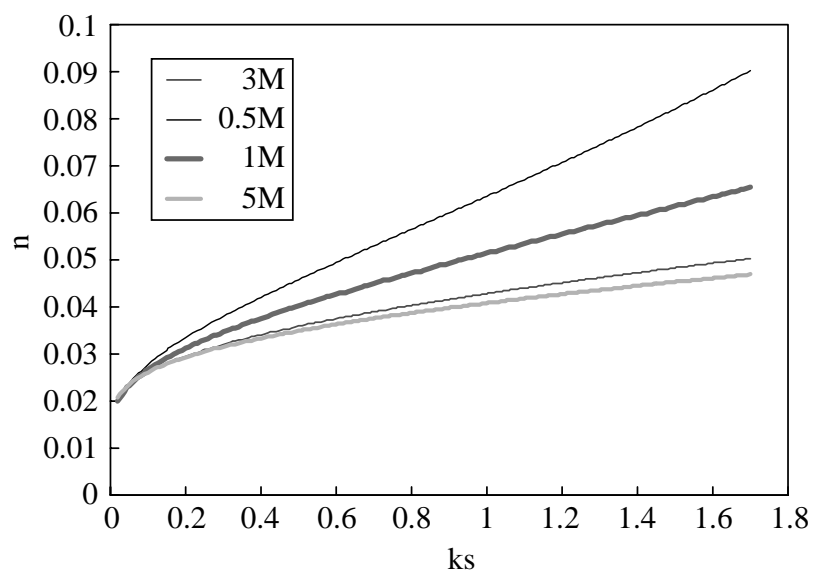

Fig. 6. Relationship between roughness, $k$, and Manning's number, $n$, at different depths.

distributed uniformly throughout the river with little difference in size whether upstream, mid-stream or downstream. From $1982 \sim 2002$, there has been continuous monitoring of Nankang River. at Nankang Bridge Station. The 20-year data reveals that the average monthly discharge of the river is 8.12 CMS. The study areas, mid-stream and downstream areas of Nankang River, are shown in Figue 7. The length of this river section is $1.5 \mathrm{~km}$ long and extends from the confluence of Nankang and Da-keng Rivers at Changan Bridge, fault location 40 to Chang-hsing Bridge (fault location 33-2). The downstream section of the river extends from fault 16 to fault 9 , the ocean.

\section{Suitability curves and model application}

Previous analogous studies selecting only a single 


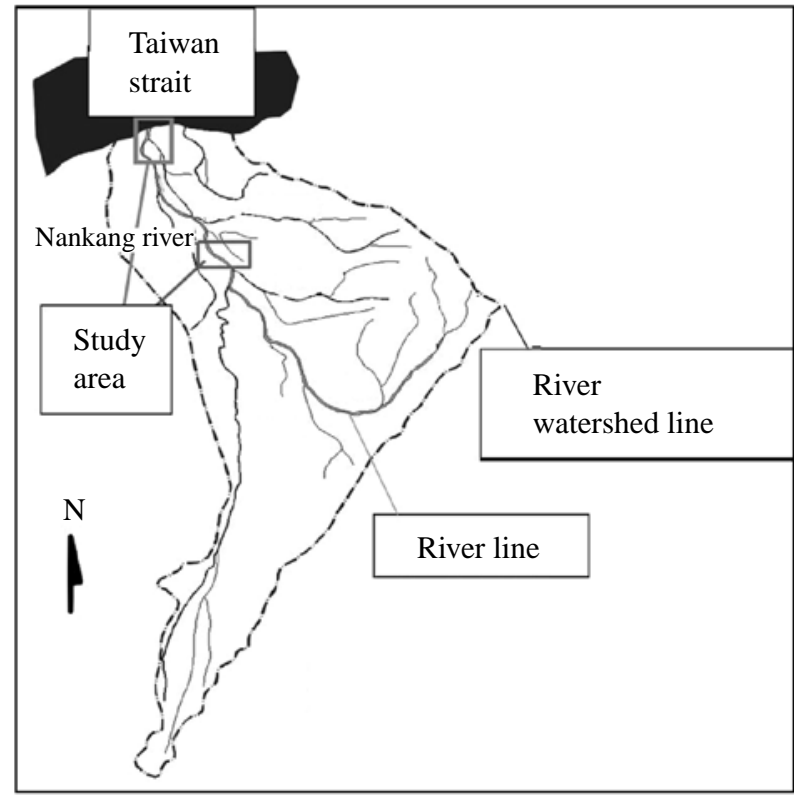

Fig. 7. Location of Nankang River watershed and study area.

target species for river habitat analysis proved problematic. In this study, a comprehensive effort is made to assess multiple factors of the habitat suitability curve on the mid- and downstream sections of the river for freshwater fish species unique to Taiwan. Habitat suitability factors for the different species of fish were categorized and analyzed from available data (journals, government reports, project reports etc). The necessary factors were classified, weighted and quantified, thus allowing us to generate suitability curves for freshwater fish species unique to Taiwan. The suitability curves for the mid and downstream sections of the river allow us to further examine the habitat conditions of the river biota. The study of suitability curves is the scope of another research the author has conducted. Yu [11] has more details for reference. The suitability curves for flow velocity, water depth and roughness are depicted below (Figure 8 10):

\section{Effect of bed roughness on habitat}

Two-dimensional hydrodynamic models can input roughness coefficients for the plane and adjust according to the actual field conditions (Table 1). They are also more accurate in calculating ecological habitat area. The reference roughness value for Nankang River is taken from Nankang River Management Report $\mathrm{r}=$ 0.035 and is used as the roughness coefficient for the whole length of the study area. These results achieved with this value is compared with the roughness values from the analysis aerial photographs and field studies.

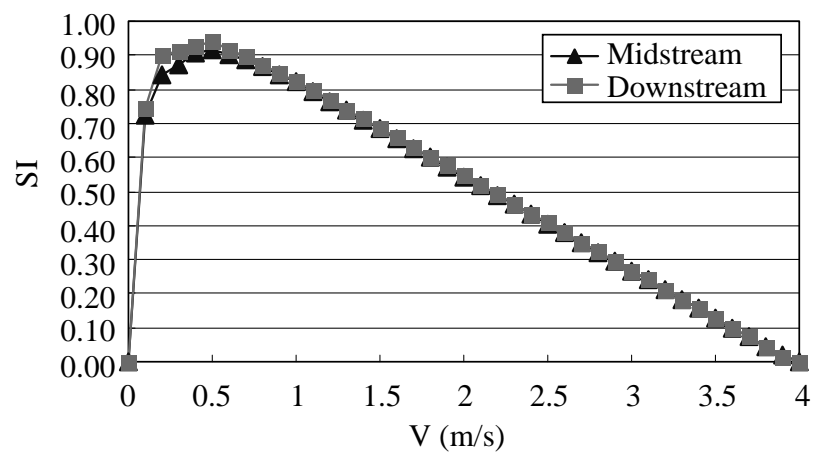

Fig. 8. Suitability Curve for flow velocity in downstream and midstream section of the northern region.

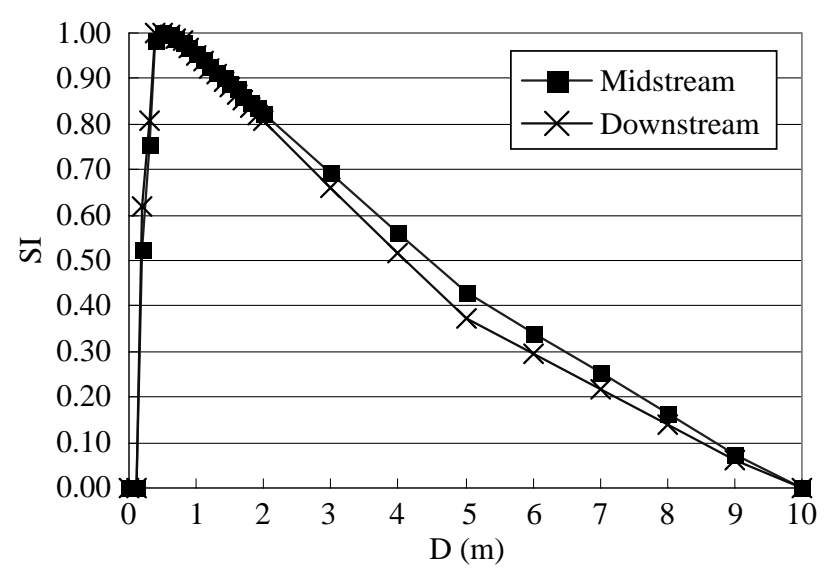

Fig. 9. Suitability Curve for water depth in downstream and midstream section of the northern region.

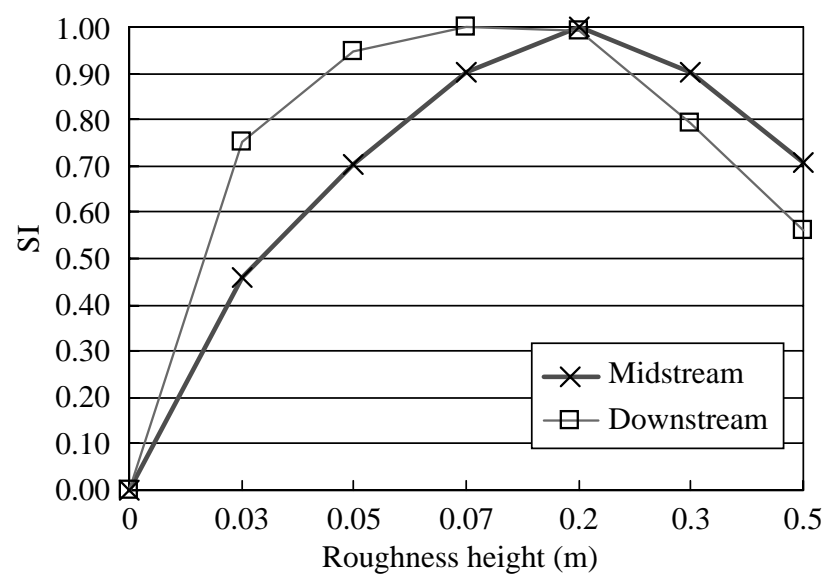

Fig. 10. Suitability Curve for substrate in downstream and midstream section of the northern region.

The model simulation for the two different input variables is shown on Figure 11 and 12. The water flow discharge chosen to simulate for WUA ranged from 1 CMS to 1110 CMS, the results of which are shown on Figure 13. 
From Figure 13, it is evident that under conditions of low water discharge, the WUA values are comparable for the two models. The primary reason for this phe-

Table 1. Roughness coefficients used for River 2D in study area

\begin{tabular}{cclc}
\hline $\begin{array}{c}\text { Map Key } \\
\text { code }\end{array}$ & Substrate & Description & Roughness \\
\hline 1 & 4.0 & Sand & 0.03 \\
2 & 5.3 & Gravel & 0.05 \\
3 & 5.7 & Cobble & 0.07 \\
4 & 6.5 & Large cobble & 0.2 \\
5 & 6.9 & Small boulder & 0.3 \\
6 & 7.2 & Large boulder & 0.5 \\
7 & 7.6 & Rocks or trees & 1.5 \\
\hline
\end{tabular}

Note: referenced from USGS, 2D Hydrodynamic/Habitat Modeling Workshop, National Conservation Training Center, March 11-13, 2002.

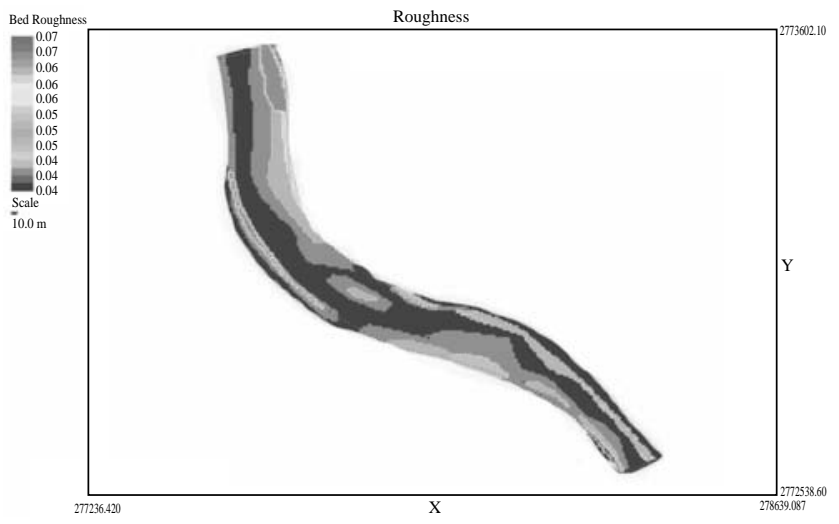

Fig. 11. Simulation using Bed roughness coefficients for specifications of each zone.

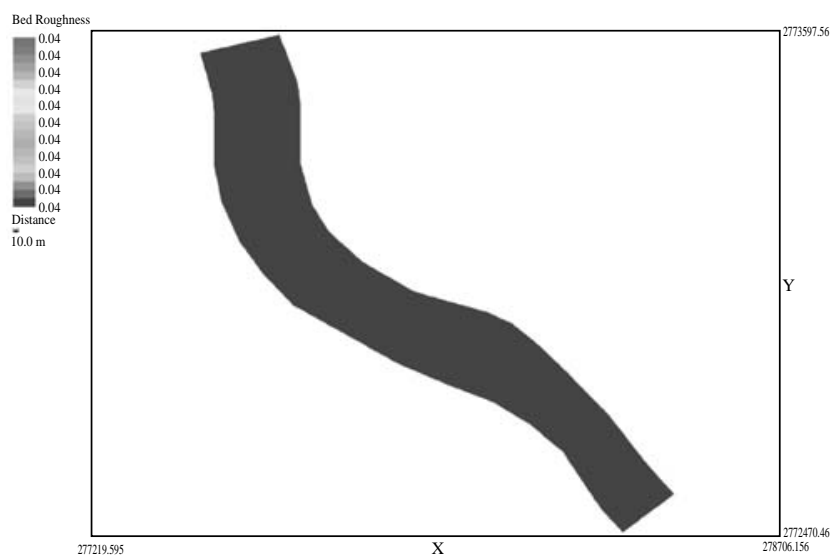

Fig. 12. Simulation using Predefined bed roughness coefficient (onedimensional model) nomenon is explained by the fact that during periods of low discharge the water flow is concentrated in the middle of the river bed, therefore, bed roughness show less variability and the habitat area the affected is also smaller. Once water discharge increases, the water flow area also increases, as does the habitat area affected by the increasing bed roughness as the water spreads out towards the banks of the river. Under these conditions, the discrepancy between the values of WUA calculated by the two models has a greater difference.

\section{Comparison of one and two-dimensional hydrody- namic and habitat models}

An assessment and comparison of one and twodimensional hydrodynamic and habitat models was undertaken for the mid and downstream sections of our study river (for WUA results example-Figure 14 and Figure 15.

The results achieved using arbitrary values of flow discharge varying from 1 to 1000 CMS can be observed on Figure 16 and Figure 17. On Figure 16, the relationship between water discharge and WUA on the mid-

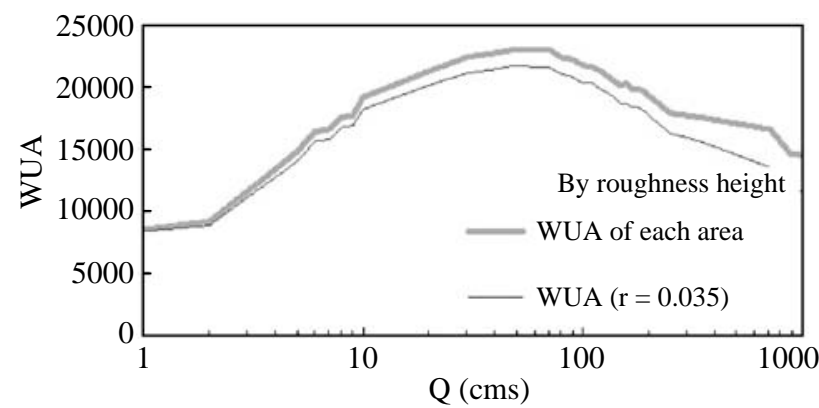

Fig. 13. Comparison of bed roughness coefficients and their effect on Weighted Usable Area.

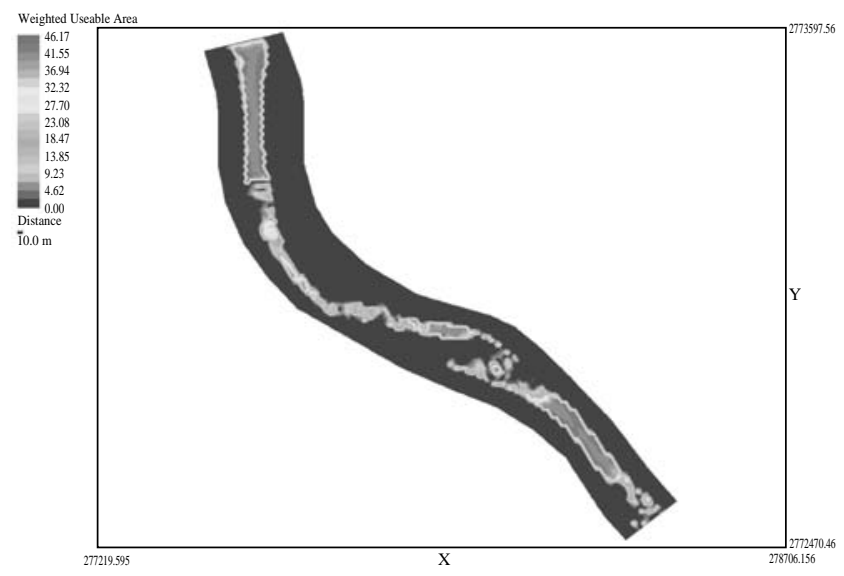

Fig. 14. WUA distribution for midstream section of study area under a water flow of 8.12 CMS. 
stream section of the river is shown. At the midstream section of the river, when the discharge varies from 1 CMS to $6 \mathrm{CMS}$, the results computed by the 2-D model are higher than those obtained by the 1-D model. As the discharge increases and passes $6 \mathrm{CMS}$, the results calculated by RHABSIM are higher than the values calculated by River 2D. The difference is highest when the water discharge reaches $100 \mathrm{CMS}$. At the downstream section of the river (Figure 17) with values of water discharge exceeding $40 \mathrm{CMS}$, the WUA calculated from the 1-D model are always higher than the WUA values from the 2-D model. One of the main reasons for this being that the influence of changes in small-scale riverbottom relief cannot be accounted for by the 1-D model. If there is a substantial variability in the profile or crosssection of the 1-D model, the divergence between the 1-D and 2-D model estimates will tend to increase. Additionally, under conditions of elevated discharge, the water flow cross-section will also increase. As stated previously, the 1-D hydrodynamic model cannot take into consideration the changes in small-scale riverbottom relief, thus data on the two main variables - flow

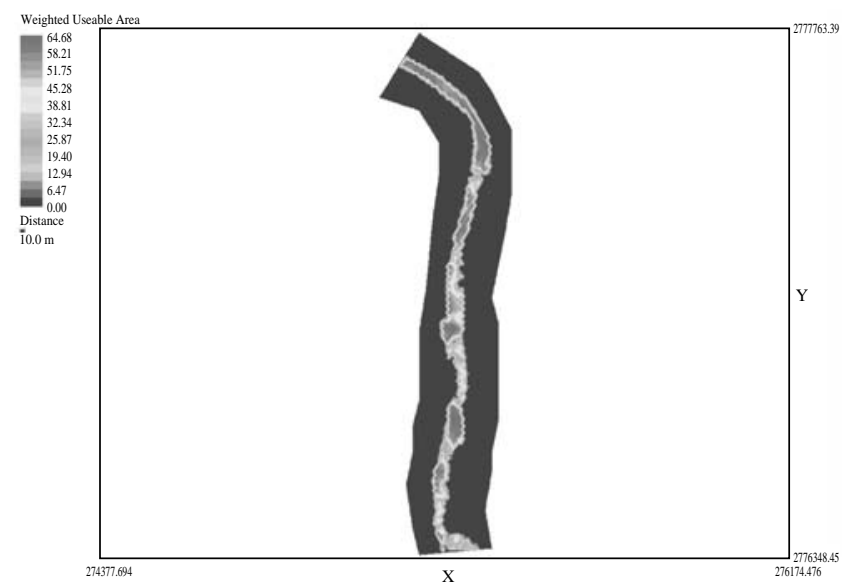

Fig. 15. WUA distribution for downstream section of study area under a water flow of 8.12 CMS.

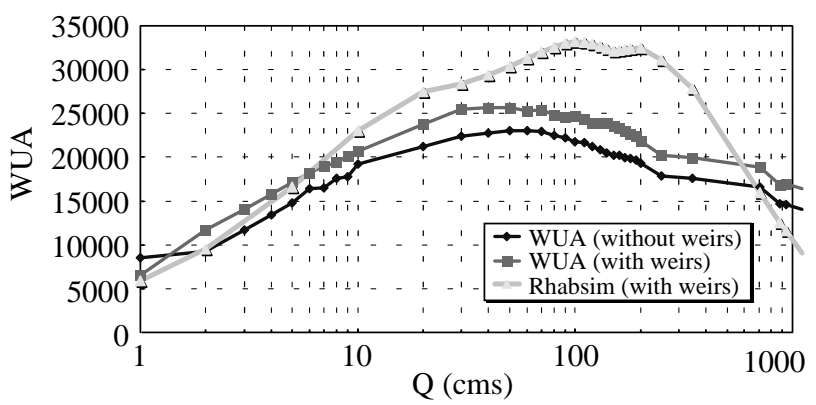

Fig. 16. Effect of artificial structures on the relationship between WUA and water flow in midstream section of river (1-D and 2-D). velocity and water depth - will not be complete. The missing pieces will be internally adjusted in the using a system of weights, but without a thorough and accurate database the evaluation by the 1-D model will be skewed. The simulation and modeling of the hydrodynamics and habitat area of the river using the 2-D model do not depend on the system of weights employed by the 1-D model. It uses a detailed DEM to model habitat conditions. Formerly, the analysis of upstream habitat water flow would be based on the evaluation of baseflow as indicated by the stationary point on the graph of WUA and water discharge. This method takes into account the sudden changes in WUA once the water flow passes the stationary point. However, under conditions of lower water flow or micro-scale habitat area, 1 -D models have a tendency to lower values of estimation, leading to errors in the determination of habitat baseflow.

\section{Effect of man-made construction on habitat conditions}

The amelioration of habitat conditions can be categorized into three main focuses: the greenification of river environment, the rehabilitation of one or several target fish species, and the restoration of river environment to mirror historical records of the river. According to the definition by the "water-soil conservation technical guideline" when the height of the weir exceeds 5 meters it is designated as a sediment control dam; when the height of the weir is below 5 meters, it is designated as a submerged dam. Nankang River for irrigation purposes, and our study also delves into the effect these artificial structures have on habitat conditions. The number of submerged dams, their width, and location has been internalized into the model using aerial photographs as reference. The habitat area for our study section are then simulated with the weir height set at 1 m. From Figure 16 it is evident that the installation of

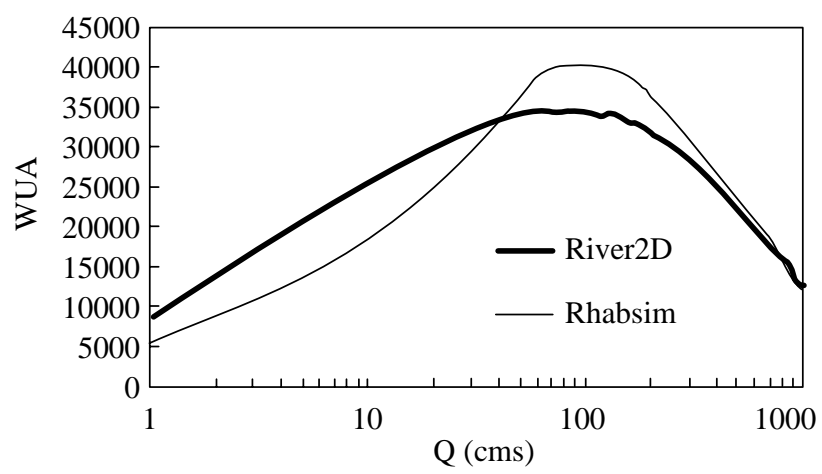

Fig. 17. Relationship between WUA and water flow in downstream section of river (1-D and 2-D). 
artificial structures within the river increases the habitat area irrespective of water discharge. We can surmise that the artificial structures actually increase the area and diversity of the available habitat.

\section{CONCLUSION AND SUGGESTIONS}

In Taiwan, the application of 1-D models to simulate river habitat conditions has been widespread. This model is suitable for simulating large-scale river environments, but is less capable of simulating microscale or complex river environments accurately. The 2D models employ a continuous flow net to further simulate topography and are more adaptable for simulating local hydrodynamics. In combination with the suitability curve, it can evaluate the habitat area of a river section. The data input for the 1-D model is relatively more complex and demanding in the initial stages, requiring a complete cross-section database to provide a reasonable accurate simulation. For the 2-D model the complications arise in the latter stages when input variables of flow velocity and water depth are needed. Nevertheless, the calculations from the 2-D model are consistently more accurate than the 1-D models for small-scale river section analysis.

The construction of weirs increased WUA in all discharge scenarios, therefore, the construction of low lying weirs in suitable locations is beneficial to the increase of WUA and ecological diversity. It has a positive effect for river lifeforms though care must be taken on the construction of fish passages.

\section{REFERENCES}

1. Huang, Z., Zhan, Y., Li, J., Shi, T., Hu, Z., and Chen, Y., "An Introduction to the Creation of DEM with Aerial
Laser Technology," Geology, Vol. 23, No. 1, pp. 34-54 (2004).(in Chinese)

2. Moody, L.F., "Friction Factors for Pipe Flow," Transactions of ASME, Vol. 66, pp. 671-684 (1944).

3. Osborne,W.S., "Distribution, Relative Abundance and Conservation Status of Corroboree Frogs, Pseudophryne Corroboree Moore (Anura: Myobatrachidae)," Australian Wildlife Research, Vol. 16, pp. 537-547 (1989).

4. Payne, T.R., Rhabsim 2.0 Riverine Habitat Simulation Software For DOS and Windows User's Manual, T.R. Payne, Associates, Arcata, CA (1998).

5. Steffler, P., R2D_Bed-Bed Topography File EditorVersion 1.23 User's Manual, University of Alberta, Canada (2002).

6. Steffler, P. and Blackburn, J., River 2D-Two-Dimensional Depth Averaged Model of River Hydrodynamics and Fish Habitat Introduction to Depth Averaged Modeling and User's Manual, University of Alberta, Canada (2002).

7. US Army Corps of Engineers Hydrologic Engineering Center, HEC-RAS River Analysis System - Hydraulic Reference Manual, Davis, CA (1995).

8. USGS, Phabsim for Windows User's Manual and Exercises, Midcontinent Ecological Science Center, USGS (2001).

9. Wu, F-C., Hu, T-Z., Li, G-S., and Li, D-W., "Using a Habitat Model to Assess River Baseflow in Taiwan," The $9^{\text {th }}$ Session of Hydrology and Engineering Conference, pp. C21-C28 (1998).

10. Yang, C.F., "The Estimation of Low River Flow and Its Application in Habitat Studies - A Case Study in Upstream Wu River," Masters Thesis, Department of Civil Engineering, National Central University, R.O.C. (2002).

11. Yu, Y.N., "The Study to Draw Up Suitability Curves of Endemic Fishes of Freshwater on Each regions in Taiwan," Masters Thesis, Department of Civil Engineering, National Central University, R.O.C. (2006). 